\title{
REVISED Cost for the treatment of actinic keratosis on the rise in
}

\section{Australia [version 2; peer review: 2 approved]}

Previously titled: Actinic keratosis on the rise in Australia

\author{
Eshini Perera1,2, Sean McGuigan², Rodney Sinclair(iD2,3 \\ ${ }^{1}$ Faculty of Medicine, The University of Melbourne, Melbourne, Parkville, 3052, Australia \\ 2Department of Dermatology, Epworth Healthcare, Melbourne, 3121, Australia \\ ${ }^{3}$ Sinclair Dermatology, Melbourne, 3121, Australia
}

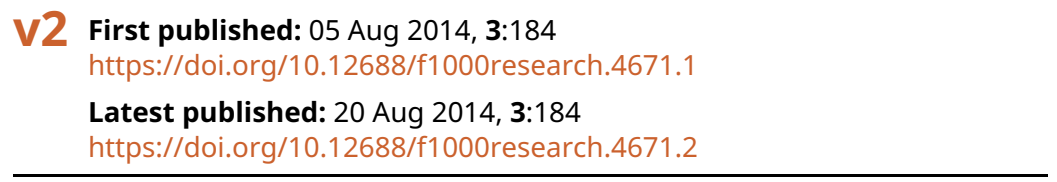

\section{Abstract}

Objectives: To report the burden and cost of actinic keratosis (AK) treatment in Australia and to forecast the number of AK treatments and the associated costs to 2020.

Design and setting: A retrospective study of data obtained from medicare Australia for AK treated by cryotherapy between 1 January 1994 and 31 December 2012, by year and by state or territory.

Results: The total number of AK cryotherapy treatments increased from 247,515 in 1994 to 643,622 in 2012 , and we estimate that the number of treatments will increase to 831,952 (95\% CI 676,919 to 986,987 ) by 2020 . The total Medicare Benefits Schedule (MBS) benefits paid out for AK in 2012 was $\$ 19.6$ million and we forecast that this will increase to $\$ 24.7$ million by 2020 (without inflation).

Conclusion: The number of AK cryotherapy treatments increased by $160 \%$ between 1994 and 2012. we forecast that the number of treatments will increase by $30 \%$ between 2012 and 2020. The rates of non-melanoma skin cancer (NMSC) and AK appear to be increasing at the same rate. During the period 2010 to 2015 AK is anticipated to increase by $17.8 \%$ which follows a similar trend to published data that forecasts an increase in NMSC treatments of $22.3 \%$.

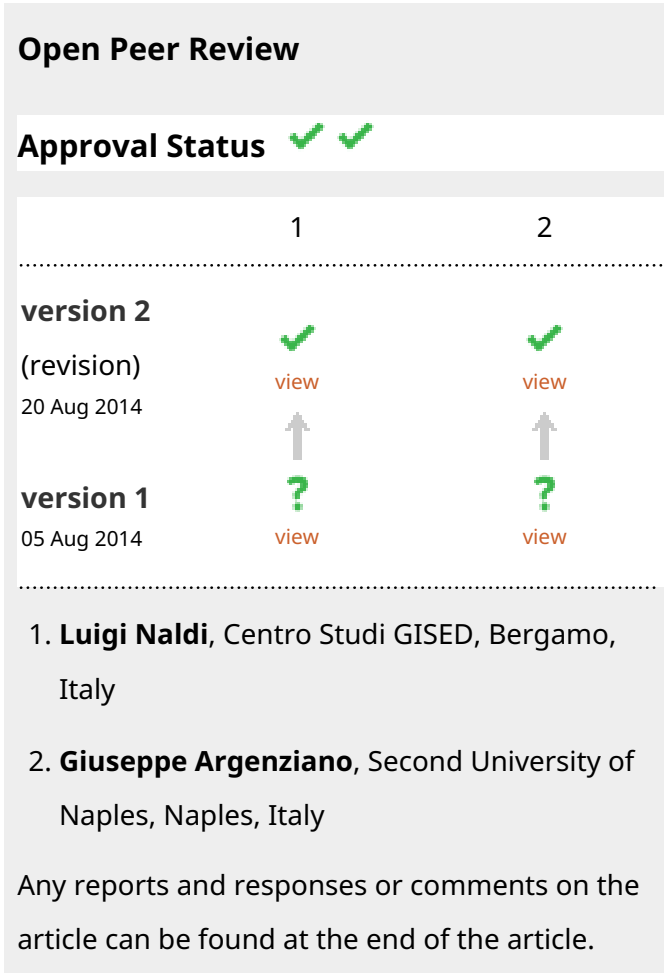

Corresponding author: Eshini Perera (eshinip@gmail.com)

Competing interests: No competing interests were disclosed.

Grant information: The author(s) declared that no grants were involved in supporting this work.

Copyright: $\odot 2014$ Perera E et al. This is an open access article distributed under the terms of the Creative Commons Attribution License, which permits unrestricted use, distribution, and reproduction in any medium, provided the original work is properly cited. Data associated with the article are available under the terms of the Creative Commons Zero "No rights reserved" data waiver (CC0 1.0 Public domain dedication).

How to cite this article: Perera E, McGuigan S and Sinclair R. Cost for the treatment of actinic keratosis on the rise in Australia [version 2; peer review: 2 approved] F1000Research 2014, 3:184 https://doi.org/10.12688/f1 000research.4671.2

First published: 05 Aug 2014, 3:184 https://doi.org/10.12688/f1000research.4671.1 


\section{REVISED Amendments from Version 1}

The reviewers' comments have been addressed in the current version of the article:

- A brief section has been added in the discussion portion of the article addressing the issue of SCC numbers.

- The abstract section has been corrected from "...by 202 " to "2020".

- The title has been changed to reflect the content of the article.

- There were no estimates on the number of treatments for modalities other than cryotherapy (including field therapy) and this is now mentioned in the article.

- "Is there any indication that some lesions were not treated at all?" A sentence has been added to the discussion stating that it is possible some lesions were not treated at all.

- Repeated treatments of the same lesion may have occurred and this is now mentioned in the article.

- The acronym PBS is now defined in the introduction.

- The final program has been corrected from "treatment of early treatment and prevention of AK is prudent" to "treatment of early lesions and prevention of AK is prudent".

See referee reports

\section{Introduction}

Actinic keratosis (AK), is one of the most common ${ }^{1}$ and most expensive skin diseases to treat. This places a high burden on the Australian population, health care system and government. Up to $60 \%$ of Australians in subtropical Queensland over the age of 40 have $\mathrm{AK}^{2}$. AK lesions are rough scaly and generally less than 1 $\mathrm{cm}$ in diameter. They are caused by chronic sun exposure and prevented by regular sunscreen use ${ }^{3}$. Multiple lesions are common. Some lesions regress spontaneously, but others progress to invasive squamous cell carcinoma (SCC). Hypertrophic AK may contain occult foci of $\mathrm{SCC}^{4}$. A systematic review of the natural history of AK estimated the risk of malignant transformation to range from $0 \%$ to $0.0075 \% /$ lesion/year ${ }^{5}$. In individuals with a history of nonmelanoma skin cancer (NMSC), the risk is up $0.53 \%$ per lesion per year ${ }^{6}$. Organ transplant recipients on systemic immuno-suppressive therapies are at increased risk of malignant transformation ${ }^{7}$.

Indications for treatment include prophylaxis of SCC, uncertainty of diagnosis, symptomatic relief and to improve cosmetic appearance. Detectable lesions are frequently associated with alterations of the surrounding skin. These surrounding subclinical lesions, or field changes, can be identified histologically and also clinically with the application of topical field therapy for $\mathrm{AK}^{8}$.

Cryosurgery with liquid nitrogen is the most widely used therapy. Clinical response varies with the duration of application, as does morbidity. One study reported cure rates of $39 \%$ for freeze times less than 5 seconds, $69 \%$ for freeze times between 5 and 25 seconds and $83 \%$ for freeze times greater than 25 seconds 9 .

Medicare Australia is a universal health insurance scheme that reimburses patients for medical fees incurred. Benefits are paid according to the Medicare Benefits Schedule (MBS) with respect to each individual Medicare item number. The item number for treatment of 10 or more solar keratosis by cryosurgery is 30192 . There is no item number for treatment of fewer than $10 \mathrm{AK}$ and therefore no reimbursement for cryotherapy treatment of less than $10 \mathrm{AK}$.

Field therapy is most useful for multiple AK lesions. Agents approved by the Therapeutics Goods Administration for field therapy include topical 5-Fluorouracil (5-FU), diclofenac sodium, inguenol mebutate and photodynamic therapy (PDT). Field therapy is not subsidized by the PBS (Pharmaceutical Benefits Scheme) and does not contribute directly to the cost to Government of treatment of AK in Australia.

There is no current published estimate of the direct cost of AK to the Australian government. We aimed to use Medicare data to report the annual numbers of AK treatments between 1994 and 2012, calculate the direct costs associated with these treatments and predict the numbers and costs from 2013 to 2020.

The risk of AK increases with age and the ageing of the Australian population may increase the burden of AK on the Australian health system.

\section{Methods}

Medicare Australia issues the total number of claims and benefits paid for each Medicare item number according to the Medicare Benefits Schedule $(\mathrm{MBS})^{10}$. The total number of claims and cost of Medicare benefits for the treatment of 10 or more premalignant lesions with an ablative therapy (MBS item number 30192) was obtained for the period 1994 to 2012 inclusive ${ }^{10}$.

The historical Medicare benefit payment data were inflated to 2012 Australian dollars, using the Reserve Bank of Australia Inflation calculator $^{11}$. For each of the SK numbers and costs historical data sets, three Auto-regressive Integrated Moving Average (ARIMA) models ${ }^{12}$ were fitted and forecasts produced for the years 2013 to 2020. The models were $\operatorname{ARIMA}(1,1,1), \operatorname{ARIMA}(0,1,1)$ and $\operatorname{ARIMA}(1,1,0)$. For each forecast series, the best fitting model was chosen on the basis of the Akaike Information Criterion (AIC) ${ }^{13}$. For both time series the AIC differences between models were extremely small and the model forecasts very similar.

Total numbers of non-melanoma skin cancer (NMSC) treatment was obtained from a study conducted by Fransen et al. ${ }^{14}$. All statistical analysis was carried out with $\mathrm{JMP}^{\circledR} \mathrm{v}$ 9.0.0.

\section{Results}

The total number of item 30192 treatment services billed to Medicare in 1994 was 247,515 , increasing to 643,622 in 2012. This represents an increase of $160 \%$. Rates remained relatively stable during the period of 2005-2009 and then began increasing again after 2010. It was estimated that the cost of treatments would reach $\$ 24.7$ million in 2020 for roughly 831,953 treatment services - an increase of $29 \%$ over the next 8 years (Table 1 and Figure 1 and Figure 2).

The total number of AK treatments billed to Medicare showed a similar increase over time to the increase seen in total NMSC treatments over the same period of time ${ }^{14}$ (Figure 3). NMSC treatment 
Table 1. Total number of AK treatments, total costs inflated, total costs without inflation and forecasts of AK numbers and costs with upper and lower 95\% confidence limits (UCL95 and LCL95).

\begin{tabular}{|c|c|c|c|c|c|c|c|}
\hline Year & $\begin{array}{l}\text { Number of AK } \\
\text { Treatments }\end{array}$ & $\begin{array}{l}\text { Number of AK } \\
\text { Treatments } \\
\text { LCL95 }\end{array}$ & $\begin{array}{l}\text { Number of AK } \\
\text { Treatments } \\
\text { UCL95 }\end{array}$ & $\begin{array}{l}\text { Total cost in } \\
\text { non-deflated } \\
\text { AU\$ }\end{array}$ & $\begin{array}{l}\text { Total cost } \\
\text { in } 2012 \text { AU\$ }\end{array}$ & $\begin{array}{l}\text { Total cost } \\
\text { in } 2012 \text { AU\$ } \\
\text { LCL95 }\end{array}$ & $\begin{array}{l}\text { Total cost } \\
\text { in } 2012 \text { AU\$ } \\
\text { UCL95 }\end{array}$ \\
\hline 1994 & 247,515 & . & & $5,592,597$ & $9,094,440$ & & . \\
\hline 1995 & 269,252 & & . & $6,168,831$ & $9,587,787$ & . & . \\
\hline 1996 & 299,863 & . & . & $6,975,529$ & $10,565,260$ & . & . \\
\hline 1997 & 311,091 & & . & $7,248,143$ & $10,953,532$ & . & . \\
\hline 1998 & 326,626 & . & . & $7,724,620$ & $11,574,041$ & . & . \\
\hline 1999 & 358,525 & . & . & $8,593,104$ & $12,687,151$ & . & . \\
\hline 2000 & 390,535 & . & . & $9,439,584$ & $13,342,203$ & . & . \\
\hline 2001 & 442,486 & . & . & $10,757,315$ & $14,562,918$ & . & . \\
\hline 2002 & 484,561 & & . & $11,857,056$ & $15,586,976$ & . & . \\
\hline 2003 & 516,626 & . & . & $12,851,675$ & $16,445,098$ & . & . \\
\hline 2004 & 563,261 & & . & $14,453,327$ & $18,071,131$ & . & . \\
\hline 2005 & 588,726 & 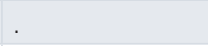 & . & $15,470,476$ & $18,835,852$ & . & . \\
\hline 2006 & 597,756 & & . & $15,991,419$ & $18,801,665$ & . & . \\
\hline 2007 & 596,683 & . & . & $16,304,737$ & $18,733,990$ & . & . \\
\hline 2008 & 591,497 & & . & $16,618,138$ & $18,298,064$ & . & . \\
\hline 2009 & 589,286 & . & . & $16,865,300$ & $18,247,035$ & . & . \\
\hline 2010 & 609,820 & . & . & $17,770,443$ & $18,681,155$ & . & . \\
\hline 2011 & 614,843 & . & . & $18,327,107$ & $18,650,174$ & . & . \\
\hline 2012 & 643,622 & . & . & $19,602,097$ & $19,602,097$ & . & . \\
\hline 2013 & 669,766 & 642,866 & 696,666 & . & $20,364,039$ & $19,399,117$ & $21,328,960$ \\
\hline 2014 & 694,371 & 643,980 & 744,763 & . & $21,037,418$ & $19,324,949$ & $22,749,887$ \\
\hline 2015 & 718,078 & 645,821 & 790,335 & . & $21,669,511$ & $19,309,150$ & $24,029,872$ \\
\hline 2016 & 741,260 & 649,137 & 833,382 & . & $22,282,359$ & $19,360,513$ & $25,204,205$ \\
\hline 2017 & 764,135 & 654,047 & 874,223 & . & $22,886,235$ & $19,471,254$ & $26,301,216$ \\
\hline 2018 & 786,831 & 660,435 & 913,227 & . & $23,485,929$ & $19,630,731$ & $27,341,128$ \\
\hline 2019 & 809,422 & 668,121 & 950,724 & . & $24,083,673$ & $19,829,435$ & $28,337,912$ \\
\hline 2020 & 831,953 & 676,919 & 986,987 & . & $24,680,509$ & $20,059,777$ & $29,301,241$ \\
\hline
\end{tabular}

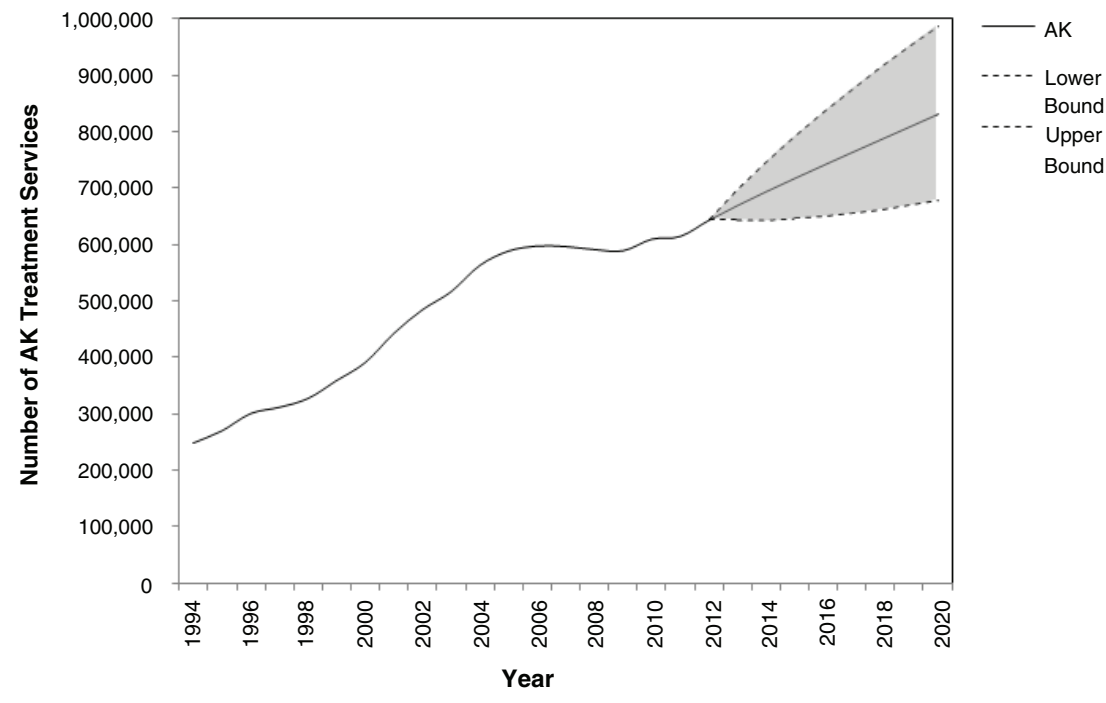

Figure 1. Total number of AK treatments from 1994-2020. Estimated treatment numbers from the period of 1994-2020. Estimated treatment numbers with $95 \% \mathrm{Cl}$ from $2013-2020$ is shaded in grey. 


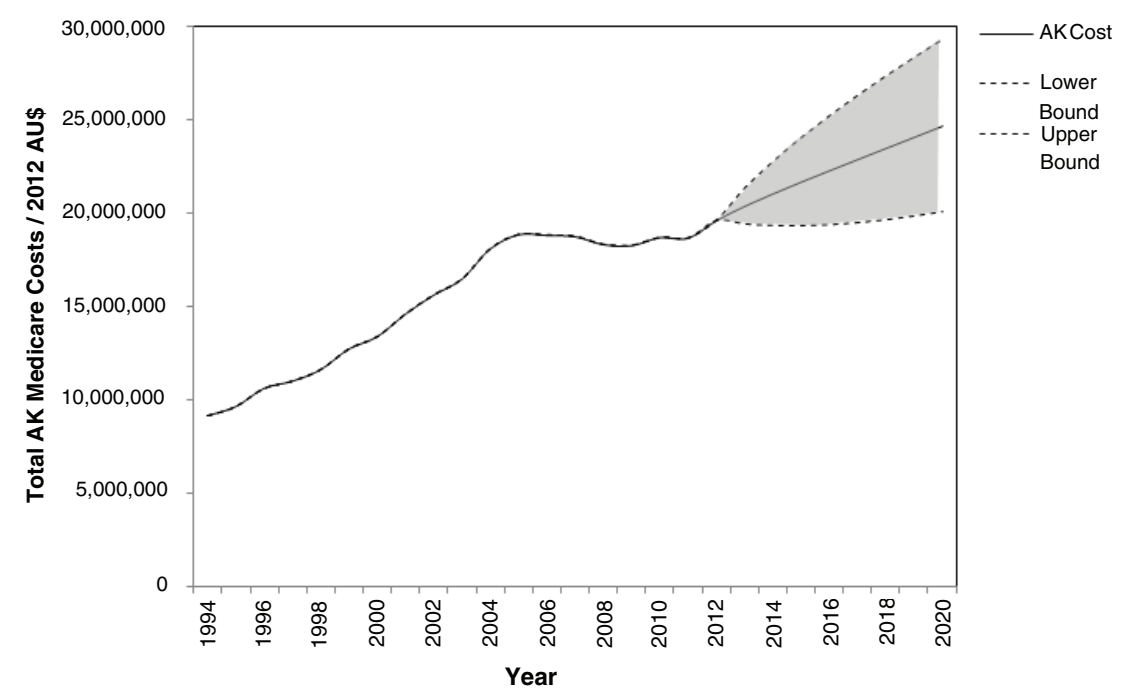

Figure 2. Total cost of AK treatments to Medicare in 2012 Australian dollars from the period of 1994-2020. Estimated costs with $95 \%$ Cl from 2013-2020 is shaded in grey.

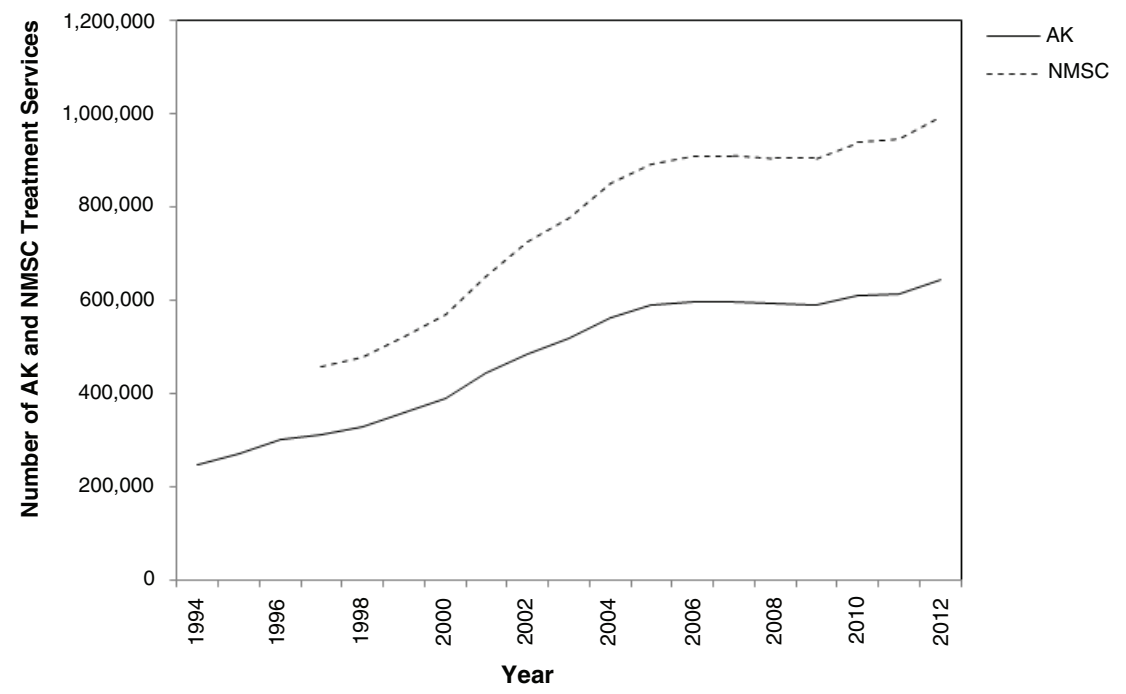

Figure 3. Total number of item 30192 services billed in Australia from 1994 to 2012. Total number of non-melanoma skin cancer treatment for 1997 to 2012 shown in dotted lines.

services continued to rise during 2005-2009 while AK treatment services remained stable.

The total number of treatment services billed for each of the Australian states and territories is illustrated in Figure 4. Approximately 293,933 treatment services were billed in NSW in 2012 and 184,233 services in Queensland compared to 1,548.

The number of AK treatments per 1,000 head was the highest in New South Wales compared to Queensland (Table 2). The number of AK treatments per 1,000 people in the Northern Territory was remarkably low, almost comparable to the number of AK treatments seen in Tasmania.
The total Medicare benefits paid for the 30192 item number in 1994 was \$5.6 million and \$19.6 million in 2012. This represents an increase of $250 \%$. NSW and Queensland received the highest amount of benefits at $\$ 9$ million and $\$ 5.6$ million respectively) while NT received the lowest amount of Medicare benefits at $\$ 49$ thousand (Figure 5).

\section{Discussion}

AK is a chronic disease. Patients with multiple AK require multiple treatment episodes. The number of item 30192 treatments for AK has increased by $160 \%$ since 1994 and is predicted to increase by a further $29 \%$ between 2012 to 2020 . NMSC has similarly been increasing over time. During the period 2010 to 2015 AK is anticipated 


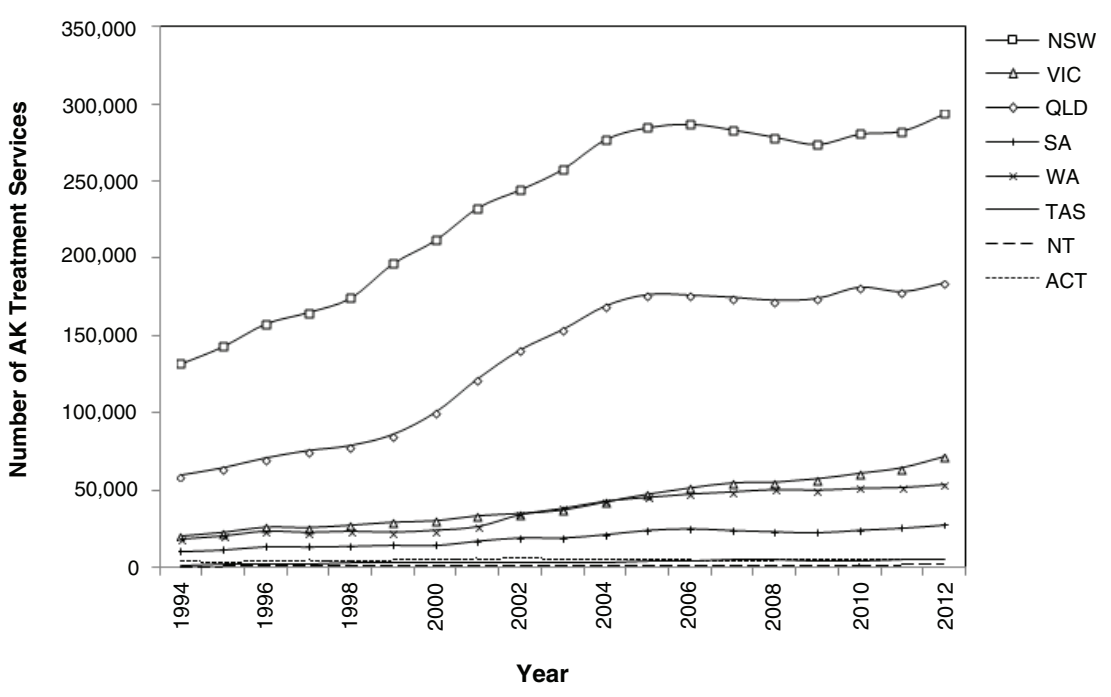

Figure 4. Total number of item 30192 services billed per year for each state from the period of 1994-2012.

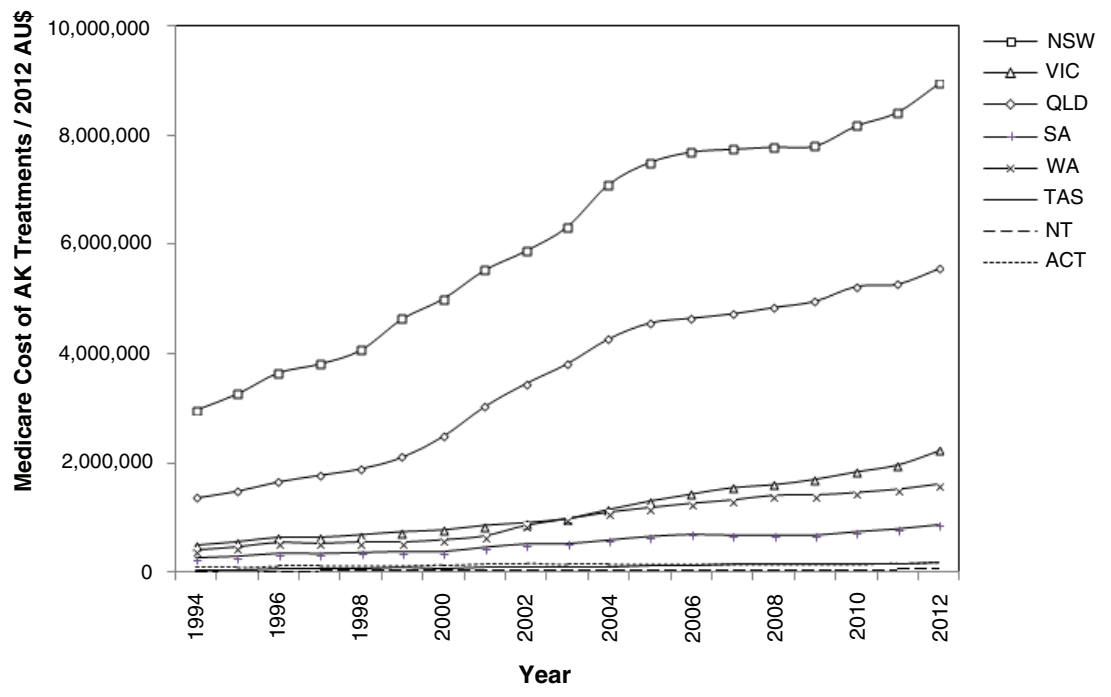

Figure 5. Total benefits paid for item number 30192 for each Australian state and territory (2012 AU\$).

to increase by $17.8 \%$ compared with an increase in NMSC treatments of $22.3 \%$ which was predicted by Fransen et al. ${ }^{14}$.

Interestingly, the rates of ablative treatment for premalignant lesions of the skin remained virtually stable during the period 2005 to 2009 , whilst the rates for NMSC treatments continued to rise during this period. One possible explanation for the trend in AK billing treatments is the introduction of new field treatment options during this period. The Therapeutic Goods Administration approved PDT with Methyl aminolevulinate $\left(\right.$ Metvix $^{\circledR}$ ) for the treatment of AK in 2003 and Imiquimod (Aldara ${ }^{\circledR}$ ) for treatment of AK in 2004.

Topical 5-FU and PDT are funded by the RPBS but not the PBS for the treatment of $\mathrm{AK}$ in repatriation members ${ }^{15}$. The contribution of these agents to the overall cost to Government of treatment of premalignant skin conditions is therefore negligible.

Also notable is the significantly higher number of AK treatment services, provided by NSW compared to Queensland. This is particularly surprising as the number of NMSC treatments recorded in Queensland continued to increase at a faster rate and the number of NMSC treatments was greater than in NSW after $2011^{10}$.

Northern Territory (NT) had the lowest number of AK treatments per 1,000 a figure that was comparable to treatment numbers seen in Tasmania. It was expected that the number of AK treatments per head would have been similar to that of Queensland because of the association between AK and ultraviolet (UV) light and the higher 
Table 2. Number of AK treatments per 1,000 people for each Australian state.

\begin{tabular}{|c|c|c|c|c|c|c|c|c|}
\hline & NSW & VIC & QLD & SA & WA & TAS & NT & ACT \\
\hline 1994 & 21.8 & 4.7 & 18.7 & 7.2 & 10.5 & 3.6 & 3.9 & 12.6 \\
\hline 1995 & 23.3 & 5.1 & 19.7 & 7.9 & 11.5 & 3.9 & 3.8 & 12.2 \\
\hline 1996 & 25.4 & 5.8 & 21.3 & 9.3 & 13.1 & 4.8 & 3.5 & 14.2 \\
\hline 1997 & 26.4 & 5.7 & 22.4 & 9.2 & 12.4 & 5.3 & 3.0 & 14.7 \\
\hline 1998 & 27.6 & 6.0 & 23.0 & 9.4 & 12.6 & 6.3 & 3.4 & 13.4 \\
\hline 1999 & 30.7 & 6.4 & 24.7 & 9.8 & 12.1 & 6.7 & 3.0 & 14.5 \\
\hline 2000 & 32.7 & 6.5 & 28.4 & 9.7 & 12.6 & 6.0 & 3.6 & 16.4 \\
\hline 2001 & 35.5 & 7.1 & 33.8 & 11.5 & 13.7 & 6.3 & 4.4 & 17.5 \\
\hline 2002 & 37.1 & 7.3 & 38.1 & 12.9 & 17.6 & 6.5 & 4.3 & 18.3 \\
\hline 2003 & 38.9 & 7.7 & 40.7 & 12.7 & 19.4 & 6.4 & 3.7 & 17.1 \\
\hline 2004 & 41.6 & 8.6 & 43.7 & 14.1 & 21.5 & 7.4 & 4.3 & 15.9 \\
\hline 2005 & 42.4 & 9.5 & 44.6 & 15.7 & 22.4 & 8.3 & 3.8 & 14.3 \\
\hline 2006 & 42.3 & 10.1 & 43.5 & 16.2 & 23.0 & 9.1 & 3.7 & 12.9 \\
\hline 2007 & 41.2 & 10.6 & 42.0 & 15.3 & 23.0 & 10.6 & 3.0 & 12.2 \\
\hline 2008 & 39.8 & 10.4 & 40.5 & 14.6 & 22.9 & 9.9 & 3.7 & 13.0 \\
\hline 2009 & 38.6 & 10.6 & 39.9 & 14.0 & 22.2 & 9.4 & 4.3 & 13.2 \\
\hline 2010 & 39.1 & 11.1 & 40.9 & 14.9 & 22.2 & 9.3 & 6.0 & 12.5 \\
\hline 2011 & 39.0 & 11.6 & 39.5 & 15.6 & 21.8 & 9.9 & 5.8 & 12.9 \\
\hline 2012 & 40.0 & 12.6 & 40.0 & 16.6 & 21.8 & 10.2 & 6.5 & 13.8 \\
\hline
\end{tabular}

levels of UV exposure in NT. Aboriginal and Torres Strait Islanders make up $30 \%$ of the population in the $\mathrm{NT}^{16}$. Although there is limited literature on the incidence of $\mathrm{AK}$ in the Indigenous population it is likely that the incidence of AK would be less that the Caucasian population as the incidence rates of NMSC and melanomas are reduced in the Indigenous population ${ }^{17}$, however this still does not account for the lower than expected treatment numbers. Most of the NT is considered rural or remote under the Australian government's remoteness classification ${ }^{18}$ and the $\mathrm{AK}$ treatment numbers may reflect the reduced access to healthcare in the NT. Furthermore, the lower number of AK treatments may also reflect the behavioural patterns of health seeking in populations living in remote areas.

One indication for the treatment of $\mathrm{AK}$ is to prevent the progression to SCC. Currently there is no up to date incidence data for SCC for the time periods studied in this paper. Further studies could examine if the treatment of AKs correspond to a reduction in cutaneous SCC. These studies would determine if the high cost of treating AK is justified.
There were three major limitations of the study. The data set did not include data on cryotherapy item numbers charged to the Department of Veterans affairs; the data did not include treatment of less than ten lesions; the Medicare item numbers could have included lesions that were treated multiple times; in addition the 30192 item number may include other premalignant conditions of the skin, however we have assumed that $\mathrm{AK}$ are the predominant skin lesion. Some AK may clinically resemble SCC and be treated surgically. We have not calculated the costs of skin surgery of AK. Our calculations did not include any patient co-payments costs incurred or the cost of the consultation. Estimates of the number of treatments for other treatment modalities were not available.

The cost to the government and the cost to the community of $\mathrm{AK}$ is increasing. We predict that the number of $\mathrm{AK}$ treatments provided by the government in 2020 will be 831,953 costing an estimated 24.7 million dollars.

An estimated $60 \%$ of SCCs develop from AK and the remaining $40 \%$ develop de novo ${ }^{19}$. Given the high risk of malignant transformation treatment of early lesions and prevention of $\mathrm{AK}$ is prudent.

Future research should focus on identifying future AK trends, cost effectiveness of field treatments versus cryotherapy for AK, the association between AK and SCCs and the role of field treatments for clinical and subclinical AKs in preventing SCCs.

\section{Data availability}

The data in this study and the study by Fransen et al. can be accessed via Medicare Australia Statistics. http://www.medicareaustralia.gov. $\mathrm{au} /$ statistics/mbs_item.shtml. The item number used was 30192; the dates used were 1994-2012.

\section{Author contributions}

The authors Eshini Perera and Rodney Sinclair were involved in writing and editing the draft of this manuscript. Sean McGuigan was responsible for the methodology and statistical calculations used in this manuscript. All authors of this research paper have directly participated in the planning, execution, or analysis of this study. All authors of this paper have read and approved the final version submitted.

\section{Competing interests}

No competing interests were disclosed.

\section{Grant information}

The author(s) declared that no grants were involved in supporting this work.
1. Neidecker MV, Davis-Ajami ML, Balkrishnan R, et al.: Pharmacoeconomic considerations in treating actinic keratosis. Pharmacoeconomics. 2009; 27(6): $451-64$.

PubMed Abstract | Publisher Full Text

2. Frost $\mathrm{CA}$, Green AC, Williams GM: The prevalence and determinants of solar keratoses at a subtropical latitude (Queensland, Australia). Br J Dermatol. 1998;
139(6): 1033-39.

PubMed Abstract | Publisher Full Text

3. Thompson SC, Jolley D, Marks R: Reduction of solar keratoses by regular sunscreen use. N Engl J Med. 1993; 329(16): 1147-51. PubMed Abstract | Publisher Full Text

4. Scarfe C, Sinclair R: Actinic Keratosis. In: Lebwohl M, Heymann W, Berth-Jones J, 
Coulson I, Editors. Treatment of Dermatological Disease. London: Harcourt Health Sciences. 2002.

5. Werner RN, Sammain A, Erdmann R, et al.: The Natural History of Actinic Keratosis: A Systematic Review. Br J Dermatol. 2013; 169(3): 502-518. PubMed Abstract | Publisher Full Text

6. Gupta AK, Paquet M, Villanueva E, et al:: Interventions for actinic keratoses. Cochrane Database Syst Rev. 2012; 12: CD004415. PubMed Abstract | Publisher Full Text

7. Lindelof B, Sigurgeirsson B, Gabel H, et al.: Incidence of skin cancer in $\mathbf{5 3 5 6}$ patients following organ transplantation. Br J Dermatol. 2000; 143(3): 513-9. PubMed Abstract | Publisher Full Text

8. Berman B, Bienstock L, Kuritzky L, et al.: Actinic keratoses: sequelae and treatments. Recommendations from a consensus panel. J Fam Pract. 2006; 55(5): S1-8.

PubMed Abstract

9. Thai KE, Fergin P, Freeman M, et al.: A prospective study of the use of cryosurgery for the treatment of actinic keratoses. Int J Dermatol. 2004; 43(9): 687-92.

PubMed Abstract | Publisher Full Text

10. Medicare Australia. Medicare Benefits Schedule item statistics reports. 2013 Reference Source

11. Reserve Bank of Australia. Inflation calculator. 2013 Reference Source

12. Beran J: Maximum Likelihood Estimation of the Differencing Parameter for
Invertible Short and Long Memory Autoregressive Integrated Moving Average Models. J R Statist Soc B. 1995; 57(4): 659-672.

Reference Source

13. Hurvich C, Tsai C: Regression and time series model selection in small samples. Biometrika. 1989; 76(2): 297-307. Publisher Full Text

14. Fransen $\mathrm{M}$, Karahalios $\mathrm{A}$, Sharma $\mathrm{N}$, et al: Non-melanoma skin cancer in Australia. Med J Aust. 2012; 197(10): 565-68.

PubMed Abstract | Publisher Full Text

15. Medicare Australia. Pharmaceutical Benefits Schedule Item Reports. 2013 Reference Source

16. Australian Bureau of Statistics. Regional statistics, Northern Territory. 2013 Reference Source

17. Australian Institute of Health and Welfare. Cancer in Australia: an overview, 2008 Canberra: AlHW, 2008. (AlHW Cat. No. CAN 42; Cancer series No. 46). 2013. Reference Source

18. Australian Institute of Health and Welfare. Rural, regional and remote health: guide to remoteness classifications. Canberra: AlHW, 2004. (AlHW Cat. No. PHE 53; Rural Health Series No. 4). 2013. Reference Source

19. Berman B, Bienstock L, Kuritzky L, et al.: Actinic keratoses: sequelae and treatments. Recommendations from a consensus panel. J Fam Pract. 2006; 55(5): S1-8

PubMed Abstract 


\section{Open Peer Review}

\section{Current Peer Review Status:}

\section{Version 2}

Reviewer Report 25 September 2014

https://doi.org/10.5256/f1000research.5487.r5918

(c) 2014 Naldi L. This is an open access peer review report distributed under the terms of the Creative Commons Attribution License, which permits unrestricted use, distribution, and reproduction in any medium, provided the original work is properly cited.

\section{Luigi Naldi}

Department of Dermatology, Centro Studi GISED, Bergamo, Italy

The authors have addressed the critical points I raised.

Competing Interests: No competing interests were disclosed.

I confirm that I have read this submission and believe that I have an appropriate level of expertise to confirm that it is of an acceptable scientific standard.

Reviewer Report 01 September 2014

https://doi.org/10.5256/f1000research.5487.r5917

(C) 2014 Argenziano G. This is an open access peer review report distributed under the terms of the Creative Commons Attribution License, which permits unrestricted use, distribution, and reproduction in any medium, provided the original work is properly cited.

\section{Giuseppe Argenziano}

Department of Dermatology, Second University of Naples, Naples, Italy

The authors nicely answered the questions posed by the reviewers.

Competing Interests: No competing interests were disclosed.

I confirm that I have read this submission and believe that I have an appropriate level of expertise to confirm that it is of an acceptable scientific standard.

\section{Version 1}


Reviewer Report 12 August 2014

https://doi.org/10.5256/f1000research.4992.r5704

(c) 2014 Argenziano G. This is an open access peer review report distributed under the terms of the Creative Commons Attribution License, which permits unrestricted use, distribution, and reproduction in any medium, provided the original work is properly cited.

\section{Giuseppe Argenziano}

Department of Dermatology, Second University of Naples, Naples, Italy

This is an interesting study outlining the rising number of treatments of actinic keratoses (AK) and non melanoma skin cancers in Australia. The paper reads well and deals with an important issue.

It would be useful to understand whether the increasing number of treated AKs actually corresponds to a decrease of invasive squamous cell carcinomas. If this is not the case, then the burden and cost of AK treatment may be not completely justified. This issue should be shortly addressed in the discussion.

Please check in the abstract, results section, "...by 202" should read "2020".

Competing Interests: No competing interests were disclosed.

\section{I confirm that I have read this submission and believe that I have an appropriate level of expertise to confirm that it is of an acceptable scientific standard, however I have significant reservations, as outlined above.}

Author Response 16 Aug 2014

Eshini Perera, The University of Melbourne, Melbourne, Parkville, Australia

Thank you kindly for reviewing our article.

We have amended the article to include your suggestions:

Incidence of SCC was briefly mentioned in the discussion. Unfortunately there is no recent data on the incidence of cutaneous SCC. There is also no data which was collected during the time frame of our study. The increasing number of AK treatments could not be correlated to the number of SCC. The abstract was corrected to read 2020.

Competing Interests: No competing interests were disclosed. 
(C) 2014 Naldi L. This is an open access peer review report distributed under the terms of the Creative Commons Attribution License, which permits unrestricted use, distribution, and reproduction in any medium, provided the original work is properly cited.

\section{Luigi Naldi}

Department of Dermatology, Centro Studi GISED, Bergamo, Italy

This is an interesting study dealing with the number of treatments reimbursed by Medicare for AK in Australia over time, and paralleling those treatments with number of treatments for SCC. As discussed by the Authors, the data presented have several limitations mainly connected with the nature of the claims data available (there is a lack of information on treatments of less than 10 AKs, and a lack of information on treatment modalities other than cryotherapy). In addition, a few points are worth of consideration:

The Title does not accurately reflect the contents of the paper. I would change it to: "Costs for the treatment of AKs on the rise in Australia"

The study is restricted to treatment of 10 or more AKs by cryotherapy. Is there any estimate of the number of treatments for modalities other than cryotherapy (including field therapy)?

Is there any indication that some lesions were not treated at all?

Were repeated treatments of the same lesions counted separately or did they simply sum up to the total?

Introduction, 5th paragraph: what does "PBS" stand for?

Methods, 3rd paragraph: as far as I understand the meaning, the reference should be to Figure 3 and not to Figure 1.

Discussion, penultimate paragraph: "treatment of early treatment and prevention of AK is prudent" should read "treatment of early lesions and prevention of AK is prudent"

Competing Interests: No competing interests were disclosed.

\section{I confirm that I have read this submission and believe that I have an appropriate level of expertise to confirm that it is of an acceptable scientific standard, however I have significant reservations, as outlined above.}

Author Response 16 Aug 2014

Eshini Perera, The University of Melbourne, Melbourne, Parkville, Australia

Thank you for reviewing our article.

We have made the following changes to our article, as per your recommendation:

The title was amended to reflect the content of the paper.

There are no estimates for the number of treatments for modalities other than cryotherapy. This was mentioned in the article. 
It is possible that some lesions were not treated and this was mentioned in the article.

- It is possible that some lesions could have been treated twice and this was mentioned in the article.

- The 3rd paragraph in the methods section was amended so that the meaning reflected what was seen in Figure 1.

The error in the discussion paragraph was corrected.

We thank you for your suggestions.

Competing Interests: No competing interests were disclosed.

The benefits of publishing with F1000Research:

- Your article is published within days, with no editorial bias

- You can publish traditional articles, null/negative results, case reports, data notes and more

- The peer review process is transparent and collaborative

- Your article is indexed in PubMed after passing peer review

- Dedicated customer support at every stage

For pre-submission enquiries, contact research@f1000.com 